\title{
Measurement of Biomarkers Troponin I, NT Pro BNP and ANP Between Horses with Signs of Respiratory Disease and Apparently Healthy Group
}

\author{
Fereydon Rezazadeh ${ }^{1, ~}$, Neda Hosseinzadeh ${ }^{2}$, Nahid Ghaderian ${ }^{3}$ \\ ${ }^{1}$ Department of Clinical Sciences, Faculty of Veterinary Medicine, University of Tabriz, Tabriz, Iran \\ ${ }^{2}$ Veterinary Pharmacology, School of Veterinary Medicine, Shiraz University, Shiraz, Iran \\ ${ }^{3}$ Specialist in Clinical-anatomical Pathology, Nour Medical Laboratory, Tabriz, Iran
}

\section{Email address:}

f_rezazdeh@tabrizu.ac.ir (F. Rezazadeh)

${ }^{*}$ Corresponding author

\section{To cite this article:}

Fereydon Rezazadeh, Neda Hosseinzadeh, Nahid Ghaderian. Measurement of Biomarkers Troponin I, NT Pro BNP and ANP Between Horses with Signs of Respiratory Disease and Apparently Healthy Group. Animal and Veterinary Sciences. Vol. 4, No. 6, 2016 , pp. 86-92. doi: $10.11648 /$ j.avs.20160406.11

Received: October 1, 2016; Accepted: October 11, 2016; Published: November 3, 2016

\begin{abstract}
Biomarkers are biological gnomons of processes or events occurring within the body. Biomarkers can be subdivided into leakage enzymes (Cardiac troponin I) and functional markers (Natriuretic peptides). Some studies were represented that these biomarkers may be changes in respiratory disorders. Therefore, present study is performed to evaluate serumic levels of cardiac biomarkers between horses with respiratory disease and apparently healthy horses. Initially 10 horses with manifestations of respiratory disease (include increasing of respiratory and heart rate, coughing, mucopurulent and purulent nasal discharge, mucosal hyperemia, increased CRT) and 8 apparently healthy horses underwent a clinical examination. Age, gender, breed and color of individual horses were recorded. CTnI and NT pro BNP were measured by chemiluminescence immunoassay but ANP was measured by ELISA kit in the serum of blood. Electrocardiogram (ECG) has been recorded in base-apex lead in the stall. The mean ages were of $2.1 \pm 00.8$ and $1.7 \pm 0.8$ in apparently healthy horses and patient groups, respectively. The mean value level of all cardiac biomarkers (cTnI, ANP and NT pro BNP) in patient group $(0.008 \pm 0.002 \mathrm{ng} / \mathrm{ml}, 280.48 \pm 79.51 \mathrm{ng} / \mathrm{L}$ and $20.34 \pm 0.68 \mathrm{pg} / \mathrm{ml})$ was higher than apparently healthy group $(0.007 \pm 0.002 \mathrm{ng} / \mathrm{ml}$, $206.92 \pm 23.01 \mathrm{ng} / \mathrm{L}$ and $20.00 \pm 0.00 \mathrm{pg} / \mathrm{ml})$. But, the statistical differences between the groups were not significant $(\mathrm{P}>0.05)$. No significant differences were found in waveforms of electrocardiograms between two groups.
\end{abstract}

Keywords: Horse, Biomarker, cTnI, NT pro BNP, ANP

\section{Introduction}

Biomarkers are distinctive biological indicators of processes or events occurring within the body. They can indicate physiological processes (such as growth and aging), or pathophysiological processes that occur with disease (e.g., cardiac damage and heart failure). Cardiac biomarkers can be helpful in the management of cardiac and non-cardiac diseases. In human medicine, there has been a push for the discovery of novel cardiac biomarkers to aid in the early detection, diagnosis, and prognosis of human cardiac diseases [1].
Myocardial injury is difficult to detect and diagnose in horses. The traditional methods that have been used to detect suspected myocardial injury are evaluation of electrocardiography (ECG) and echocardiography. These methods have limitations and therefore attempts have been made to find more sensitive markers for myocardial injury in the horse and biomarkers have provided new options to detect cardiac injury in different species [2, 3, 4, 5, 6-7].

Many biological markers of disease are currently available or are on the horizon for application in several different types of diseases in human and veterinary medicine. The most important of these biomarkers in large animal medicine include L-lactate, cTnI, serum amyloid A (SAA), triglyceride, 
creatinine, and glucose [8]. In recent years cardiac troponin I (cTnI), a protein involved in the interaction between actin and myosin during contraction, has gained interest as a clinical marker for myocardial injury in different species. cTnI is known to leak out from injured myocardial cells and has been shown to be a sensitive and specific marker for myocardial injury in humans and dogs $[9,10,11-12]$.

The amino acid sequence for equine cTnI has recently been characterized and evidence supports the use of commercial human assay systems to measure equine cardiac troponin I [13]. Despite the sensitivity and specificity of the troponins for cardiomyocyte necrosis, they have not proven very useful in diagnosing heart failure, or indeed many heart diseases, in veterinary medicine. This is likely because most cardiac diseases in animals do not cause significant cardiomyocyte necrosis and, therefore, the troponins would not be expected to increase. To evaluate heart disease that does not induce cardiomyocyte necrosis, one needs a functional biomarker that increases as atrial and ventricular remodeling occurs; this biomarker would then be expected to increase with various heart diseases and heart failure. cTnI may also be of use in other conditions that the cardiovascular system is not involved primarily [14].

Biomarkers are may also be of use to detect reduced exercise tolerance due to cardiovascular disease and although they may be used to determine the prognosis of therapeutic procedures [15]. In dogs and cats, NT pro ANP and NT pro BNP can help differentiate animals with dyspnea from heart failure from animals with dyspnea from extra-cardiac causes. Additionally, the natriuretic peptides have been shown to have some ability to distinguish between animals with subclinical disease and animals without disease; their performance for this being much better in cats. The natriuretic peptides' ability to screen for subclinical heart disease (usually valve disease) in horses and the ability to discriminate dyspnea caused by heart failure from dyspnea caused by other diseases has yet to be fully determined [16, 17, 18-19].

The aims of the present study were to study concentration of cTnI, NT pro BNP and ANP in serum of apparently healthy horses and to see if respiratory disease influences the concentration of them.

\section{Materials and Methods}

\subsection{Animals}

In this study, 18 horses (14 male and 4 female) of three different breeds, Arab, Kurd and cross-breed were selected from 10 equestrian horse jokey clubs located in Tabriz area in Iran during October 2014 to March 2015. The horses underwent a clinical examination with specific focus on the cardiovascular and respiratory systems (without to diagnoses of definitive disease). Patients selected on the bases of clinical signs. Total horses were categorized into two groups; those with clinical signs of respiratory disease (increased respiratory rate, coughing, nasal mucopurulent discharge, increased heart rate, mucosal hyperemia and hyperthermia) and hear of exocordial sound considered as patient group but those without the aforementioned signs considered as control group. Therefore 10 horses $(55.60 \%)$ and 8 horses $(44.40 \%)$ made up patient and control groups, respectively. The horse's categorized bases of their dental formula were aged $<5$ years, 5-10 years and 10-15 years with the mean age of $2.1 \pm 00.8$ and $1.7 \pm 0.8$ in control and patient groups, respectively.

\subsection{Clinical Examination}

Clinical examination, were done in all of the horses and paying special attention to the cardiovascular and respiratory systems. Types of nasal discharge (serous, seromucos, mucopurulent and purulent) was registered for categorized of mild, moderate or severe situation of respiratory system compromised. Respiratory sounds were auscultated from the lungs. Crackle and wheeze were auscultated from several patient horses. The horses were suspected to have recurrent airway obstruction (RAO) or IAD (inflammatory airway disease); they had biphasic respiration and severe coughing. After that, heart rate and rhythm were evaluated through auscultation of heart. Conjunctive of eyes was used to evaluate the mucosal color (normal, little hyperemic and severe hyperemic) for evaluation of cardiovascular system. The capillary refill time (CRT) was evaluated by pressing the gingiva of maxillae.

\subsection{Electerocardiography (ECG)}

The ECG was recorded using a manual ECG unit (San-ie ECG, E21, medical equipment service company, Iran), with electrodes placed in a base-apex conformation which is routinely used in large animals. The negative electrodes were placed on the cardiac base, on the left side of the chest, and positive electrode were placed just to jugular veins on the left side (basal electrode). The gel was used as an extra safety to secure the electrodes. The sensitivity, speed and lead of ECG unit were fixed $1 / 2,25 \mathrm{~mm} / \mathrm{sec}$ and I respectively; thus resting ECG was recorded. The ECG recordings were subjected to analysis.

\subsection{Blood Sampling}

Venous blood $(10 \mathrm{ml})$ were collected from the jugular vein of each animal, $2 \mathrm{~mL}$ volume of blood collected into an EDTA tube (EDTA K3, Italy), and the remaining $8 \mathrm{~mL}$ of blood was placed in plain tubes (Z Serum Clot Activator, VACUETTE $^{\circledR}$, Austria) for the measurement of concentration of cardiac biomarkers. The blood samples were transferred as soon as possible to the laboratory and preserved at $4^{\circ} \mathrm{C}$ until the tests done. The samples were centrifuged for $10 \mathrm{~min}$ at $3000 \mathrm{~g}$. After centrifugation, the serum was removed and stored at $-70^{\circ} \mathrm{C}$ until ready for test.

\section{5. cTnI, ANP and NT Pro BNP Assays}

The concentrations of cTnI were measured with immunoassay method in chemiluminescence (Liaison) through diagnostic kit (Saluggia, S.P.A, Italy, DiaSorin, Inc.) 
and NT pro BNP were measured with diagnostic kit (Lianberis, Gwynedd, LL55 4EL, UK) in Immulite 2000. The concentration of ANP was measured with kit (Human ANP ELISA kit, angzhou Eastbiopharm Inc., USA).

\subsection{Statistical Method}

SPSS19 statistical analysis software was used for analyzing obtained results. Data of serum cTnI, NT pro BNP and ANP presented as mean $\pm 2 \mathrm{SD}$. Comparisons of cardiac biomarkers between two groups were conducted using independent-samples $\mathrm{T}$ Test and Mann-Withney U. The graphs used in this study are Boxplots. Values of $\mathrm{P}<0.05$ were considered significant.

\section{Results}

The mean serumic level of each of cardiac biomarkers is shown in Table 1. For all horses, cTnI concentrations ranged from 0 to $0.01 \mathrm{ng} / \mathrm{ml}$. All of horses had cTnI concentrations below the reference range $(<0.034 \mathrm{ng} / \mathrm{ml})$. For all horses, NT pro BNP concentrations ranged from 20 to $23.40 \mathrm{pg} / \mathrm{ml}$. All of horses had NT pro BNP concentrations below the reference range $(<28.50 \mathrm{ng} / \mathrm{ml})$. All of horses had ANP concentrations in the medium laboratory range (120-340 ng/L) except two horses which were exceeded the medium laboratory range $(>340 \mathrm{ng} / \mathrm{L})$. Recently the reference range of ANP had been determined in horses (15.6-26.4 ng/ml and 7.2-34 ng/ml) through two different methods (Gehlen et. al. 2007; Trachsel et. al. 2011) [37, 38]. Totally, the mean serumic level of all cardiac biomarkers (cTnI, ANP and NT pro BNP) in patient group $(0.008 \pm 0.002 \mathrm{ng} / \mathrm{ml}, 280.48 \pm 79.51$ $\mathrm{ng} / \mathrm{L}$ and $20.34 \pm 0.68 \mathrm{pg} / \mathrm{ml})$ were higher than control group $(0.007 \pm 0.002 \mathrm{ng} / \mathrm{ml}, 206.92 \pm 23.01 \mathrm{ng} / \mathrm{L}$ and $20.00 \pm 0.00$ $\mathrm{pg} / \mathrm{ml}$ ) as shown in figures 1,2 and 3 but the statistical differences between the groups were not significant $(p>0.05)$.

Table 1. Mean, minimum and maximum of serumic levels of cardiac biomarkers in horses with signs of respiratory disease and apparently healthy horses.

\begin{tabular}{|c|c|c|c|c|c|c|}
\hline Parameter & group & Number & Minimum & Maximum & Mean $\pm(2 S E)$ & P value \\
\hline \multirow{2}{*}{$\mathrm{cTnI}^{\mathrm{a}}$} & Control & 8 & 0.00 & 0.01 & $0.00 \pm 0.00$ & \multirow{2}{*}{0.428} \\
\hline & Patient & 10 & 0.00 & 0.01 & $0.00 \pm 0.00$ & \\
\hline \multirow{2}{*}{ NT pro $\mathrm{BNP}^{\mathrm{b}}$} & Control & 8 & 20.00 & 20.00 & $20.00 \pm 0.00$ & \multirow{2}{*}{0.063} \\
\hline & Patient & 10 & 20.00 & 23.40 & $20.34 \pm 0.68$ & \\
\hline \multirow{2}{*}{$\mathrm{ANP}^{\mathrm{c}}$} & Control & 8 & 164.14 & 268.56 & $206.92 \pm 23.01$ & \multirow{2}{*}{0.083} \\
\hline & Patient & 10 & 157.71 & 595.27 & $280.48 \pm 79.51$ & \\
\hline
\end{tabular}

Significance set at $\mathrm{P} 0.05^{*}$

cTnI, NT pro BNP and ANP are expressed by $\mathrm{ng} / \mathrm{ml}, \mathrm{pg} / \mathrm{ml}$ and $\mathrm{ng} / \mathrm{L}$ respectively.

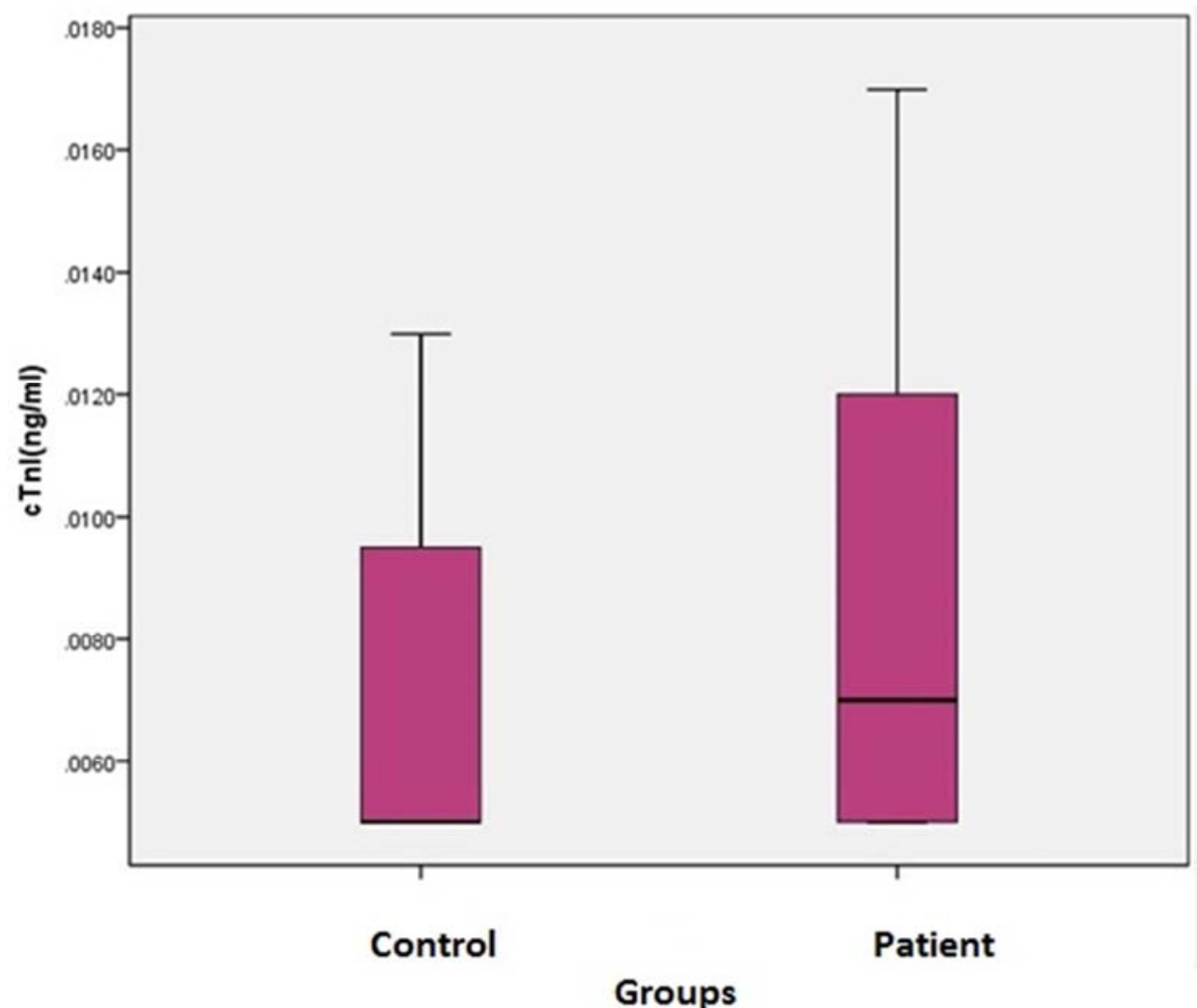

Fig. 1. Plot of comparison of cTnI concentration between two groups. 


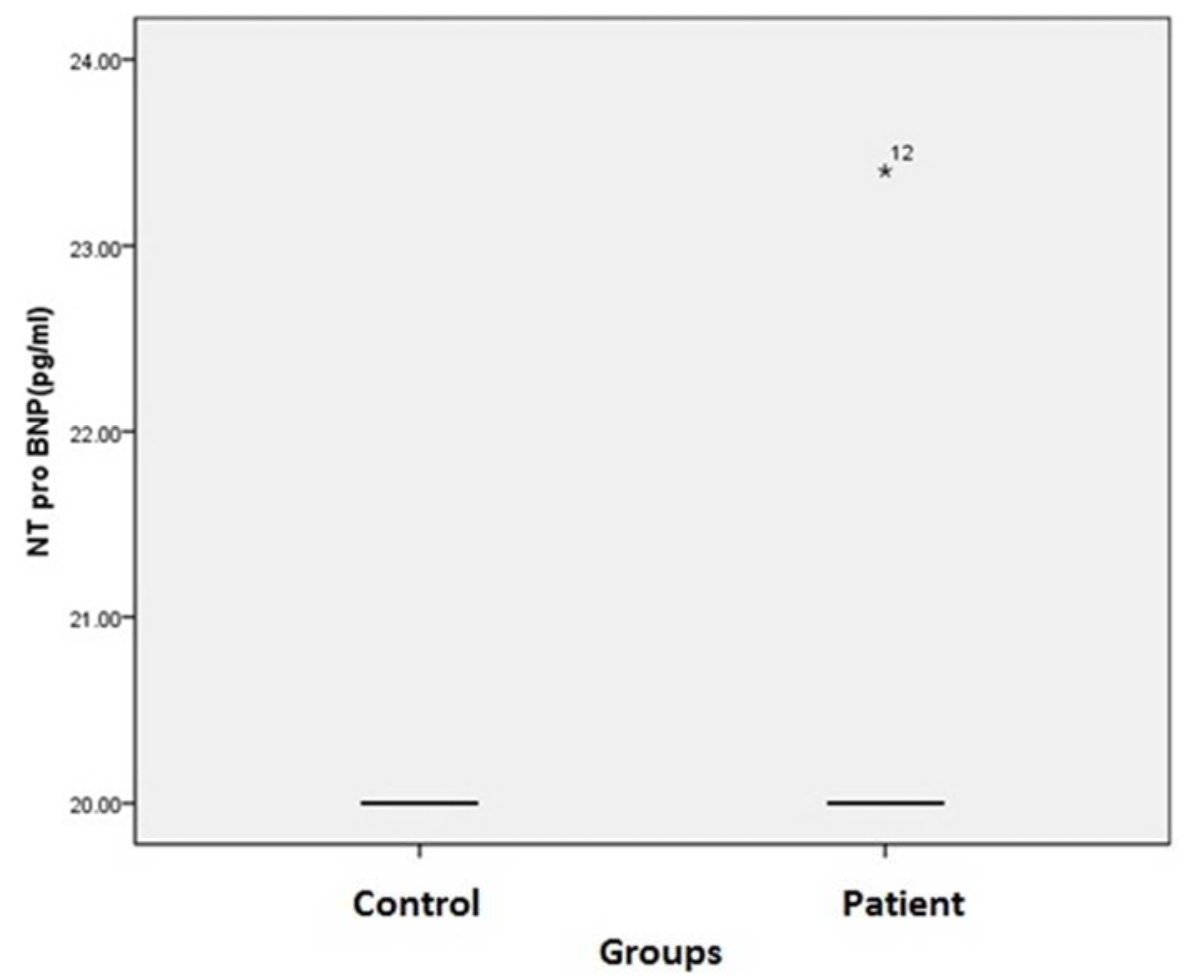

* Indicates that serumic level of NT pro BNP in one of the patient horses is higher.

Fig. 2. Plot of comparison of NT pro BNP concentration between two groups.

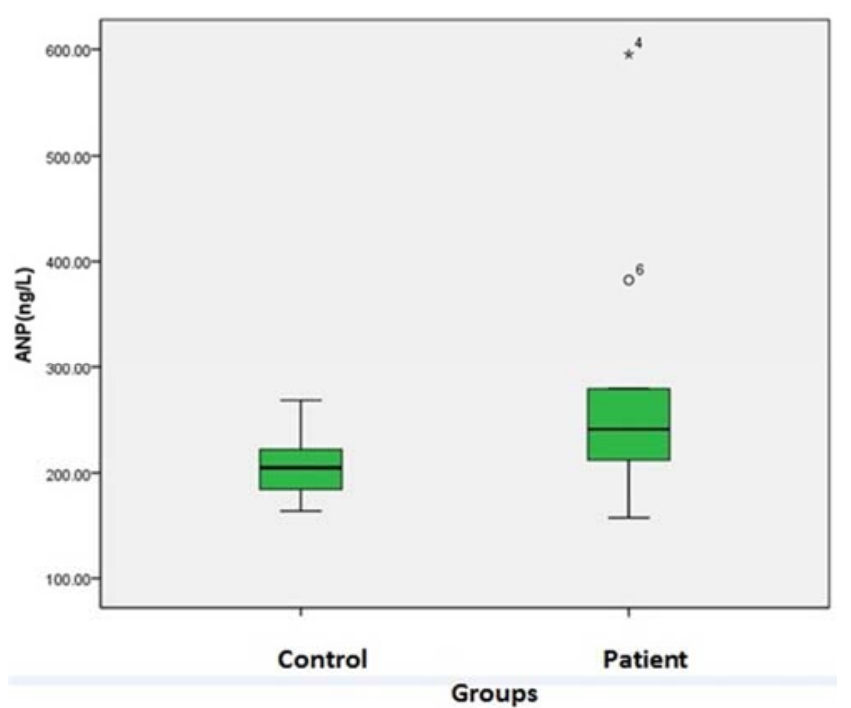

* and ${ }^{\circ}$ indicates that serumic level of ANP in two of the patient horses are higher.

Fig. 3. Plot of comparison of ANP concentration between two groups.

No changes had been found in the waveforms and rhythm of heart rate of electrocardiograms recorded from horses suspected to have IAD or other respiratory disease. The only electrocardiographic finding was sinus dysrhythmia (the intervals between QRS complexes are equal) which is due to increased vagal tone in horse and is known as the most common physiologic dysrhythmia in horse (Fig.4). Sinus dysrhythmia was the only electrocardiographic finding in the ECG of a horse suspected to have murmur in the left heart (Fig. 5). Totally, there was no significant difference between the shapes of waves; the only electrocardiographic finding was physiologic sinus dysrhythmia that was shown in $50 \%$ and $80 \%$ of control and patient groups respectively.

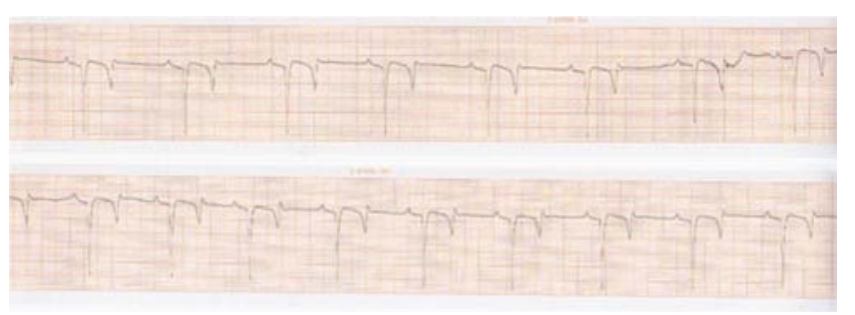

Fig. 4. ECG of a horse suspected to have IAD in present study (base-apex lead I, sensitivity: 1/2, speed: $25 \mathrm{~mm} / \mathrm{sec}$ ).

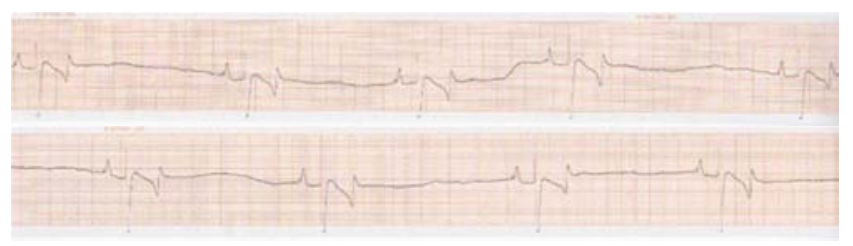

Fig. 5. ECG of a horse suspected to have murmur in the left heart (baseapex lead I, sensitivity: 1/2, speed: $25 \mathrm{~mm} / \mathrm{sec}$ ).

\section{Discussion}

Cardiac troponin I (cTnI), a myocardial polypeptide, is a highly sensitive and specific biomarker of myocardial injury in people and dogs. The structure of cTnI is highly conserved across species, and equine myocardium has high reactivity with human immunoassays (Rishniw and simpson, 2005) 
[13]. Increased serum cTnI is an indicator of myocardial injury occurred in animals. In this study, the serum cTnI of all horses were reported in reference range. Despite our results indicated that IAD (RAO) did not cause myocardial injury but it could be said that myocardial injury was mild so increased level of cTnI was not significant. In a study conducted by Phillips et. al. (2003) [22], serum cTnI concentrations were determined with a colorimetric immunoassay with sensitivity of $0.04 \mathrm{ng} / \mathrm{mL}$. Phillips and his colleagues found that the serum cTnI concentrations in racetraining horses were not significantly different from those of pastured horses and when two groups were combined, mean cTnI concentration (+/-2SD) was $0.047+/-0.085 \mathrm{ng} / \mathrm{mL}$. In present study, the mean cTnI concentration $(+/-2 \mathrm{SD})$ was $0.00+/-0.00 \mathrm{ng} / \mathrm{ml}$ in apparently healthy group.

In a study conducted by Hassanpour (2014) [23], the mean serumic level of cardiac troponin in patient group with strangles was higher than control group and difference between them was significant. Corpulmonale has been reported in several domestic species, most recently in the horse [24]. Cardiac function in horses with airway inflammation has received limited attention, but the few studies that were performed identified right ventricle hypertrophy (Sage et. al, 2006) [24]. Cornelisse et. al (2000) [25] found that serum cTnI concentrations in a horse with myocardial disease increased so suggested that assessment of cardiac troponin concentrations may be a useful tool in the evaluation of horses with suspected myocardial disease. The aim of present study was to evaluate the effects of respiratory disease on cardiovascular system; if the cardiovascular system had been involved secondarily and myocardium injured, the concentration of cTnI would be increased but the concentration of cTnI of all horses were in reference range.

Van Der Vekens et. al. (2015) [26] demonstrated that despite large quantitative differences, cTnI and cTnT are both useful for detection of myocardial damage in horses but this finding is not in parallel with the findings of Gehlen and et. al. (2007). The reference range of cTnI has been determined in dogs, cats and horses [20, 25-37]. In present study, the reference range of cTnI was determined $(<0.034 \mathrm{ng} / \mathrm{ml})$ by human kit and chemiluminescence method. The reference range of cTnI should be determined by every laboratory. In a study conducted by Rishniw and Simpson (2005), a 6-aminoacid N-terminal deletion unique to the horse was identified. This deletion was outside the epitope region of cTnI recognized by most commercial immunoassays and did not affect the ability of a commercial analyzer system to detect recombinant equine cTnI. It was hypothesized that sequence similarity between horses and other mammals would be very high, which would support the use of commercial cTnI detection systems in equine medicine [13].

Ver Elst and et. al. (2000) indicated that cTnI increases in sepsis which is in agreement with the results of Fernandes and et. al. (1999). In present study, despite the signs of respiratory infection (purulent discharge and coughing) had been manifested, the increased level of serum cTnI in patient group was not significant $[27,28]$.
ANP and BNP will be increased when the blood is accumulated in ventricles. BNP has diagnostic value to distinguish between failure of right ventricle and hypertension of pulmonary artery; thus it is hypothesized that BNP has diagnostic and prognostic values (Yap et. al. 2004) [29]. BNP is more preferred than ANP in clinical medicine due to its higher half-life (Woodard and Rosado 2007) [30]. BNP not only increased in cardiac failures but also may increase in pulmonary hypertension, sepsis and hyperthyroidism (Felker et. al. 2006; Nagaya et. al. 2000) $[31,32]$. In human medicine, the prevalence of cardiovascular disease is common among patients influenced by COPD and it is an indicator of poor prognosis of respiratory disease (Holguin et. al. 2005;Sin et. al. 2006) [33, 34]. In present study, it could be hypothesized that the patient horses specially those suspected to have IAD (RAO), did not have cardiovascular disease because no abnormalities found in ECG and serum cTnI were in reference range. Hypoxia and pulmonary vascular contraction might cause pulmonary hypertension and right ventricular failure in cases severely influenced by IAD and BNP increases (Chaouat and et. al. 2008) but in present study, NT pro BNP did not increase in none of patient animals [35].

The use of ANP in human medicine is limited (Saito, 2010) [36]. Recently the reference range of ANP had been determined in horses $(15.6-26.4 \mathrm{ng} / \mathrm{ml}$ and $7.2-34 \mathrm{ng} / \mathrm{ml})$ with two different methods (Gehlen et. al. 2007; Trachsel et. al. 2011) [37, 38]; in this study, human research ELISA kit had been used and serum ANP of all horses had been reported in reference range. Bando et. al. (1999) found the cases influenced by Cor-pulmonale, the difference of mean level between control and patient groups was significant; our result can be agreement with the result of Bando and may be the respiratory disease had not progressed into Corpulmonale. In according to Tulevski et. al. (2011), ANP and BNP increases when the blood pressure exceeded in right ventricle;it may be concluded that pressure of blood in right ventricle did not increase but this propose should be confirmed by echocardiography [39, 40]. Regarding to the specific half-life of each cardiac biomarker in serum and plasma, the blood sample should be taken in appropriate time after respiratory or cardiovascular disease occurred.

\section{Conclusions}

In conclusion, the results of this study indicate that, the mean serumic level of all cardiac biomarkers (cTnI, ANP and NT pro BNP) in patient group were higher than control group but the statistical differences between the groups were not significant; It may be due to small population of horses.

\section{Acknowledgments}

The authors thanks from vice-chancellor of the University of Tabriz for his kindly collaboration and supports for this research. 


\section{References}

[1] S. A. Jesty. Cardiac biomarkers in equine medicine. The Veterinary Journal. Vol. 192, 2012, pp. 131-132.

[2] F. Apple. Tissue specificity of cardiac troponin I, cardiac troponin $\mathrm{T}$ and creatine kinase-MB. Clinica Chimica Acta. Vol. 284, 1999, pp. 151-159.

[3] J. E. Adams, G. S. Bodor, V. G. Davila-Roman, J. A. Delmez, F. S. Apple, J. H. Ladenson, A. S. Jaffe. Cardiac troponin I. A marker with high specificity for cardiac injury. Circulation. Vol. 88, 1993, pp. 101-106.

[4] G. O. Evans. Biochemical assessment of cardiac function and damage in animal species. A review of the current approach of the academic, governmental and industrial institutions represented by the Animal Clinical Chemistry Association. Journal of Applied Toxicology. Vol. 11, 1991, pp. 15-21.

[5] T. H. Lee, L. Goldman. Serum enzyme assays in the diagnosis of acute myocardial infarction. Recommendations based on a quantitative analysis. Annals of Internal Medicine. Vol. 105, 1986, pp. 221-233.

[6] K. Nakai, K. Nakai, Y. Nagane, W. Obara, M. Sato, K. Ohi, N. Matsumoto, N. Takanashi, C. Itoh. Serum levels of cardiac troponin I and other marker proteins in patients with chronic renal failure. Clinical and Experimental Nephrology. Vol. 8, 2004, pp. 43-47.

[7] S. A. Argiroudis, J. E. Kent, D. J. Blackmore. Observations on the isoenzymes of creatine kinase in equine serum and tissues. Search Results. Equine Veterinary Journal. Vol. 14, 1982, pp. 317-321.

[8] R. M. Radcliffe, B. R. Buchanan, V. L. Cook, T. J. Divers. The clinical value of whole blood point-of-care biomarkers in large animal emergency and critical care medicine. Journal of Veterinary Emergency and Critical Care. Vol. 25, 2015, pp. 138-151. doi: 10.1111/vec.12276.

[9] J. Mair, N. Genser, D. Morandell, J. Maier, P. Mair, P. Lechleitner, C. Calzolari, C. Larue, E. Ambach, F. Dienstl, B. Pau, B. Puschendorf. Cardiac troponin I in the diagnosis of myocardial injury and infarction. Clinica Chimica Acta. Vol. 245, 1996, pp. 19-38.

[10] V. Ricchiuti, S. W. Sharkey, M. M. Murakami, E. M. Voss, F. S. Apple. Cardiac troponin I and T alterations in dog hearts with myocardial infarction: correlation with infarct size. American Journal of Clinical Pathology. Vol. 110, 1998, pp. 241-247.

[11] K. E. Schober, B. Kirbach, G. Oechtering. Noninvasive assessment of myocardial cell injury in dogs with suspected cardiac contusion. Journal of Veterinary Cardiology. Vol.1, 1999, pp. 17-25.

[12] P. J. O’Brien, Y. Landt, J. H. Ladenson. Differential reactivity of cardiac and skeletalmuscle fromvarious species in a cardiac troponin I immunoassay. Clinical Chemistry. Vol. 43, 1997, pp. 2333-2338.

[13] M. Rishniw and K. W. Simpson. Cloning and sequencing of equine cardiac troponin I and confirmation of its usefulness as a target analyte for commercial troponin I analyzers. Journal of Veterinary Diagnostic Investigation. Vol. 17, 2005, pp. 582584 .
[14] M. Serra, S. Papakonstantinou, M. Adamcova, P. J. O'Brien. Veterinary and toxicological applications for the detection of cardiac injury using cardiac troponin. The Veterinary Journal. Vol. 185, 2010, pp. 50-57.

[15] S. A. Jesty, M. S. Kraus, A. R. Gelzer. Measurement of plasma cardiac troponin I concentration by use of a point-of-care analyzer in clinically normal horses and horses with experimentally induced cardiac disease. American Journal of Veterinary Research. Vol. 71, 2010, pp. 55-59.

[16] R. Prosek, D. D. Sisson, M. A. Oyama, P. F. Solter. Distinguishing cardiac and noncardiac dyspnea in 48 dogs using plasma atrial natriuretic factor, B-type natriuretic factor, endothelin, and cardiac troponin-I. Journal of Veterinary Internal Medicine. Vol. 21, 2007, pp. 238-242.

[17] T. M. Zimmering, F. Meneses, I. J. Nolte, D. Simon. Measurement of N-terminal proatrial natriuretic peptide in plasma of cats with and without cardiomyopathy. American Journal of Veterinary Research. Vol. 70, 2009, pp. 216-222.

[18] V. Chetboul, F. Serres, R. Tissier, H. P. Lefebvre, C. C. Sampedrano, V. Gouni,, L. Poujol,, G. Hawa, J. L. Pouchelon. Association of plasma N-terminal Pro-B-type natriuretic peptide concentration with mitral regurgitation severity and outcome in dogs with asymptomatic degenerative mitral valve disease. Journal of Veterinary Internal Medicine. Vol. 23, 2009, pp. 984-994.

[19] D. S. Trachsel, B. Grenacher, M. A. Weishaupt, C. C. Schwarzwald. Plasma atrial natriuretic peptide concentrations in horses with heart disease: A pilot study. Vet. J. Vol. 192, 2012, pp. 166-170.

[20] K. E. Schober, C. Cornand, B. Kirbach. Serum cardiac troponin I and cardiac troponin $\mathrm{T}$ concentrations in dogs with gastric dilatation-volvulus. J. Am. Vet. Med. Assoc. Vol. 221, 2002, pp. 381-388.

[21] M. Rishniw, S. C. Barr, K. W. Simpson. Cloning and sequencing of the canine and feline cardiac troponin I genes. American Journal of Veterinary Research. Vol. 65, 2004, pp. 53-58.

[22] W. Phillips, S. Giguère, R. P. Franklin, J. Hernandez, D. Adin, J. Peloso. Cardiac troponin I in pastured and race-training Thoroughbred horses. Journal of Veterinary Internal Medicine. Vol.17, 2003, pp. 597-599.

[23] A. Hassanpour. A study on the serumic levels of cardiac troponin and some enzymes in horses with strangles. Indian journal of fundamental and applied life sciences. Vol. 4, 2014, pp. 7-9.

[24] A. M. Sage, S. Valberg, D. W. Hayden. Echocardiography in a horse with corpulmonale from recurrent airway obstruction. Journal of Veterinary Internal Medicine. Vol. 20, 2006, pp. 694-696.

[25] C. J. Cornelisse, H. C. Schott, N. B. Olivier, T.P. Mullaney, A. Koller, D. V. Wilson, F. J. Derksen. Concentration of cardiac troponin $\mathrm{I}$ in a horse with a ruptured aortic regurgitation jet lesion and ventricular tachycardia. Journal of the American Veterinary Medical Association. Vol. 217, 2000, pp. 231-235.

[26] N. Van Der Vekens, A. Decloedt, S. Ven, D. De Clercq, G. Van Loon. Cardiac troponin I as compared to troponin T for the detection of myocardial damage in horses. Journal of Veterinary Internal Medicine. Vol. 29, 2015, pp. 348-54. doi: $10.1111 /$ jvim. 12530 . 
[27] K. M. Ver Elst, H. D. Spapen, D. N. Nguyen. Cardiac troponins I and $\mathrm{T}$ are biological markers of left ventricular dysfunction in septic shock. Clinical Chemistry. Vol. 46, 2000, pp. 650-657.

[28] C. J. Fernandes, N. Akamine, E. Knobel. Cardiac troponin: a new serum marker of myocardial injury in sepsis. Intensive Care Medicine. Vol. 25, 1999, pp. 1165-1168.

[29] L. B. Yap, D. Mukerjee, P. M. Timms, H. Ashrafian, J. G. Coghlan. Natriuretic peptides, respiratory disease, and the right heart. CHEST. Vol. 126, 2004, pp. 1330-1336.

[30] G. E. Woodard, J. A. Rosado. Recent advances in natriuretic peptide research. Journal of Cellular and Molecular Medicine. Vol. 11, 2007, pp. 1263-1271.

[31] G. M. Felker, J. W. Petersen, D. B. Mark. Natriuretic peptides in the diagnosis and management of heart failure. Canadian Medical Association Journal. Vol. 175, 2006, pp. 611-617.

[32] N. Nagaya, T. Nishikimi, M. Uematsu. Plasma brain natriuretic peptide as a prognostic indicator in patients with primary pulmonary hypertension. Circulation. Vol.102, 2000, pp. 865-870.

[33] F. Holguin, E. Folch, S. C. Redd. Comorbidity and mortality in COPD-related hospitalizations in the United States, 19792001. CHEST. Vol. 128, 2005, pp. 2005-2011.

[34] D. D. Sin, N. R. Anthonisen, J. B. Soriano. Mortality in COPD: role of comorbidities. European Respiratory Society. Vol. 28, 2006, pp. 1245-1257.
[35] A. Chaouat, R. Naeije, E. Weitzenblum. Pulmonary hypertension in COPD. European Respiratory Society. Vol. 32, 2008, pp. 1371-1385.

[36] Y. Saito. Roles of atrial natriuretic peptide and its therapeutic use. Journal of Cardiology. Vol. 56, 2010, pp. 262-270.

[37] H. Gehlen, T. Sundermann, K. Rohn, P. R. Stadler. Plasma atrial natriuretic peptide concentration in warm-blood horses with heart valve regurgitations. Journal of Veterinary Cardiology. Vol. 9, 2007, pp. 99-101.

[38] D. S. Trachsel, B. Grenacher, M. A. Weishaupt, C. C. Schwarzwald. Plasma atrial natriuretic peptide concentrations in horses with heart disease: A pilot study. The Veterinary Journal. 2011, pp. 1-5.

[39] M. Bando, Y. Ishii, Y. Sugiyama. Elevated plasma brain natriuretic peptide levels in chronic respiratory failure with corpulmonale. Respiratory Medicine. Vol. 93, 1999, pp. 507514.

[40] I. I. Tulevski, M. Groenink, E. E. Van Der Wall. Increased brain and atrial natriuretic peptides in patients with chronic right ventricular pressure overload: correlation between plasma neurohormones and right ventricular dysfunction. Heart. Vol. 86, 2001, pp. 27-30. 